\title{
The Impact of Contemporary Communication Technology on Undergraduate Students' Dating Violence Episodes: An Exploration of Routine Activity Theory
}

\author{
Nancy Mayoyo, Jackton Ogeno, Francis Likoye \\ Department of Educational Foundations, Kenyatta University, Nairobi, Kenya \\ Email: mayoyo.nancy@ku.ac.ke, ogeno.jackton@ku.ac.ke, malenya.francis@ku.ac.ke
}

How to cite this paper: Mayoyo, N., Ogeno, J., \& Likoye, F. (2020). The Impact of Contemporary Communication Technology on Undergraduate Students' Dating Violence Episodes: An Exploration of Routine Activity Theory. Open Journal of Social Sciences, 8, 161-175.

https://doi.org/10.4236/jss.2020.89011

Received: August 7, 2020

Accepted: September 14, 2020

Published: September 17, 2020

Copyright $\odot 2020$ by author(s) and Scientific Research Publishing Inc. This work is licensed under the Creative Commons Attribution-NonCommercial International License (CC BY-NC 4.0). http://creativecommons.org/licenses/by-nc/4.0/ (c) (i) \&) Open Access

\begin{abstract}
The study was an empirical exploration of the kinds of communication technologies used in perpetrating different forms of Cyber Dating Abuse. The study was guided by Routine activities theory which states that the daily activities that individuals engage in make them susceptible to Cyber Dating Abuse. The study utilized data collected from 315 dating undergraduate students from selected universities in Nairobi City County, Kenya. The research design used in the study was a cross-sectional descriptive survey. The results showed that respondents mainly used smartphones to constantly exchange calls, text messages and instant messages on social media. Instant messaging on WhatsApp was most frequently used to perpetrate Cyber Dating Abuse. The findings indicate that the social interaction afforded by the use of various digital media made it possible for motivated offenders to encounter suitable victims (in this case their partners). An extended use of digital media by the victims increased their visibility and accessibility to the offender. A Pearson's Correlation Coefficient $r(313)=0.20, p \leq 0.001$ established that the amount of time spent online was statistically and significantly positively associated with higher Cyber Dating Abuse victimization. Since digital media keeps evolving with chances that the youth will keep using it, this implies that Cyber Dating Abuse victimization is likely to persist. This calls for a need for universities to have critical discussions on how Cyber Dating Abuse, can be prevented to avoid its escalation which may lead to worse consequences on students' psychological health and academic outcomes.
\end{abstract}

\section{Keywords}

Cyber Dating Abuse, Communication Technology, Routine Activities Theory 


\section{Introduction}

The advancement in technology in the contemporary world has provided appropriate tools for perpetrators to harass, threaten and socially embarrass their victims in their intimate relationships. This is so as the availability of different contemporary communication technologies encourage constant communication among lovers. Much of this communication has been moved online as the youth communicate regularly through e-mail, text messages, phone calls, instant messages and social media. It is in this daily interaction as part of their regular routine that the high usage exposes victims to a new form of intimate partner violence referred to as cyber dating abuse.

Cyber Dating Abuse is a form of intimate partner violence that involves the use of digital media to harass, threaten and cause psychological harm and social embarrassment to a partner. Moreover, the greater the amount of time an individual spends using technology, the higher their level of exposure to CDA which has negative consequences on their psychological health. Communication technologies have proved to be powerful tools in enhancing connectivity which has a positive effect in fostering relationships. However, their use also poses a great risk to people's lives as they can be tools of destruction used by partners to harm others.

Cyber Dating Abuse has emerged as a social problem that afflicts dating students worldwide. Reed (2015), in her study of high school students still in USA established that $73 \%$ of females and $66 \%$ of males of 1162 students were victims of CDA. A study of 433 College students conducted in Europe-Spain established that over $50 \%$ had suffered from CDA victimization (Borrajo, Gamez-Guadix, Pereda, \& Calvete, 2015a). While a considerable amount of research has been carried out on Cyber Dating Abuse in America and Europe, the same cannot be said of other continents particularly Africa. Thus, there is a dearth of empirical studies that have investigated CDA among adolescents and young adults.

Reviewed studies indicate that CDA is majorly carried out through the use of mobile phones via calls, Social Media, SMS, sexting and instant messages. Mobile phones are frequently used not only in verbal fights with a partner but also in threatening, harassing and stalking (Draucker \& Martsolf, 2010). Moreover, smartphones have the capability of doing more than make calls and send texts. They can be used to send Multimedia Message Service (MMS) messages, make video calls and access sites like Facebook (FB), Twitter and Snap chat among others (Vermaat, 2014).

A study by Picard (2007) showed that $10 \%$ of 382 respondents were physically threatened through social media while $30 \%$ reported to have received 10 or more SMS in an hour from partners to monitor their whereabouts and activities. 25\% were called names, harassed or demeaned through SMS and 22\% reported to have been coerced to sext. Lucero et al. (2014) found monitoring, sexting and password sharing to be part of CDA. The respondents in both studies were adolescents. Draucker and Martsolf (2010) established that about 4\% of 56 youth 
used IM to establish relationships, limit partner's access to themselves and reconcile after a violent episode or breakup. A study by Borrajo, Gámez-Guadix, Pereda, and Calvete (2015a) of 433 dating university students found out that passwords were used to spy and control a partner. Behaviours consisting control and monitoring were normalized and justified by "a romanticized view of love" or perceived as a joke. Another study among university students in Spain established that most CDA behaviours (52.04\%) were perpetrated using social networking sites; $40.92 \%$ were carried through messaging applications like WhatsApp while 7.04\% of behaviours were through email (Burke, Wallen, Vail-Smith, \& Knox, 2011). This paper therefore sought to explore how the regular usage of technology in the students' day to day activities as outlined in the routine activities theory (Cohen and Felson, 1979) exposed a suitable victim to a motivated offender hence making them susceptible to cyber dating abuse. It also sought to find out what kinds of communication technologies were used in perpetrating different forms of Cyber Dating Abuse among Kenyan undergraduate students.

\section{Methodology}

\subsection{Participants}

Data were drawn from a convenient sample of 356 undergraduate students from three universities from Nairobi City County, Kenya. Final analysis was based on 315 respondents who indicated that they had a dating history. The respondents were aged 18 - 35. 201 respondents (63.8\%) were aged 18 - 21, 99 (31.4\%) were aged 22 - 24 while $15(4.8 \%)$ were aged above 25 . The average mean age was 21 $(\mathrm{SD}=1.99)$. The mode was 20 . The study's protocol was approved by the Kenyatta University Ethical Committee.

\subsection{Procedure}

A descriptive cross-sectional design utilizing both quantitative and qualitative data collection methodologies was used in this study. This was appropriate as it enabled the study to describe the undergraduate students' routine use of communication technology and how it relates to cyber dating abuse. A self-administered questionnaire was used to collect quantitative data. Levels of Cyber Dating Abuse were measured using the Cyber Dating Abuse Scale (CDAS) adopted from a validated measure of cyber dating abuse behaviours by Borrajo et al. (2015b) and Reed et al. (2015). The scale was modified to fit the study and was made up of 32 parallel items focusing on perpetration and victimization behaviours among intimate partners. Further, 6 same-sex focus group interviews comprising 8 participants each were used to collect qualitative data. The discussions took between 45 minutes and an hour. The interviews were audio recorded and transcribed verbatim.

\section{Results}

The study sought to obtain an overview on the student's use of digital technolo- 
gies and their communication patterns. This was crucial in providing information on technologies used in the perpetration of CDA. The findings indicated that all the respondents with dating experience 315 (100\%) owned mobile phones and 314 (99.7\%) had access to the internet. Data from the FGD revealed that this was possible due to the availability of free $\mathrm{Wi}$-Fi in all three universities. Some students reported having access to free Wi-Fi in their rented hostels. Additionally, they used data bundles provided by mobile service providers to access the internet. Also, 312 (99\%) used social media to connect with their partners. Respondents used mobile phones to make calls, exchange text messages as well as access social networking sites to connect with their partners.

\subsection{Texting (SMSing)}

The study sought to find out the extent to which the respondents interacted with their partners through Short Messaging Services (SMS). They were asked to state the number of SMSs they exchanged in a single day. Table 1 shows the results.

The findings show that majority (94.3\%) of the respondents corresponded with their intimate partners using text messages. 48.9\% exchanged between 1 20 text messages daily. $32.1 \%$ sent between $21-200$ texts per day. A very small number (13.3\%) sent over 200 texts per day. On the frequency of texting, of the 311 who gave a response to this question, $21.9 \%$ texted at least once per day, $63.7 \%$ sent texts several times a day. Only $8.7 \%$ sent texts several times an hour while $5.8 \%$ did not exchange texts at all. Findings from the focus group discussions revealed that for majority of the respondents, text messaging was a more preferred mode of communication than calling.

\subsection{Calling}

The study sought to find out the frequency of communication between partners through phone calls. The results are as indicated in Table 2.

The findings as shown in Table 2 indicate that 163 (52.9\%) respondents called their partners at least once per day, 135 (43.8\%) called several times a day. 7 $(2.3 \%)$ called several times an hour while $3(1 \%)$ did not call at all. 7 (2.2\%) of the 315 with dating experience did not respond to the question.

\subsection{Access to the Internet and Social Media}

The study sought to find out if the respondents had access to internet and if they used social media. The findings showed that 314 (99.7\%) had access to internet on their mobile phones, tablets or laptops. The study also sought to find out the time spent on social media during a typical weekday and during a typical weekend. Table 3 indicates the results as follows.

The findings revealed that on weekdays 158 (50.2\%) of the respondents spent more than 3 hours on the internet with this number rising to 207 (65.7\%) during the weekend. 99 (31.4\%) spent between 1 hour to 3 hours on the weekdays with $67(21.3 \%)$ spending the same time during the weekend. On weekdays, $58(18.4 \%)$ 
Table 1. Frequency of sending SMS to current or ex-partner per day.

\begin{tabular}{ccc}
\hline & Frequency & Valid Percentage \\
\hline No text & 18 & 5.7 \\
$1-20$ & 154 & 48.9 \\
$21-200$ & 101 & 32.1 \\
$201-250$ & 19 & 6.0 \\
500 & 23 & 7.3 \\
TOTAL & 315 & 100 \\
\hline
\end{tabular}

Table 2. Frequency of calling current or ex-partner per day.

\begin{tabular}{ccc}
\hline & Frequency & Valid Percentage \\
\hline Not at all & 3 & 1.0 \\
Once per day & 163 & 52.9 \\
Several times a day & 135 & 43.8 \\
Several times an hour & 7 & 2.3 \\
Total & $\mathbf{3 0 8}$ & $\mathbf{1 0 0}$ \\
\hline
\end{tabular}

Table 3. Hours spent online on social media during a typical WEEKDAY and WEEKEND. How many hours do you spend on social media? $\mathrm{n}=315$.

\begin{tabular}{ccccc}
\hline & \multicolumn{2}{c}{ WEEKDAY } & \multicolumn{2}{c}{ WEEKEND } \\
\cline { 2 - 5 } & Frequency & Percentage & Frequency & Percentage \\
\hline Less than half an hour & 16 & 5.1 & 14 & 4.4 \\
Half an hour to 1 hour & 42 & 13.3 & 27 & 8.6 \\
1 - 3 hours & 99 & 31.4 & 67 & 21.3 \\
More than 3 hours & 158 & 50.2 & 207 & 65.7 \\
Total & 315 & 100 & 315 & 100 \\
\hline
\end{tabular}

spent less than an hour while only 41 (13\%) spent the same time on weekends. Further analysis indicated that the average total time spent on social media per week was 18 hours 5 minutes, and 139 (44.1\%) spent 24 hours 30 minutes per week.

Additionally, the respondents were asked to indicate whether they used social media to connect with their partners. The expected responses were a "yes" or "no". The findings indicate that majority $312(99 \%)$ of them used social media with their partners with a negligible number $3(1 \%)$ indicating they did not use any. Also, the respondents were asked to indicate all the social media they frequently used. Figure 1 illustrates the findings as follows:

Tick all the social media and instant messaging applications you use regularly with your partner. $n=312$.

The findings indicate that majority of the respondents 290 (92.9\%) listed WhatsApp; 185 (59.3\%) listed Facebook; Instagram was listed by 157 (50.3\%) 


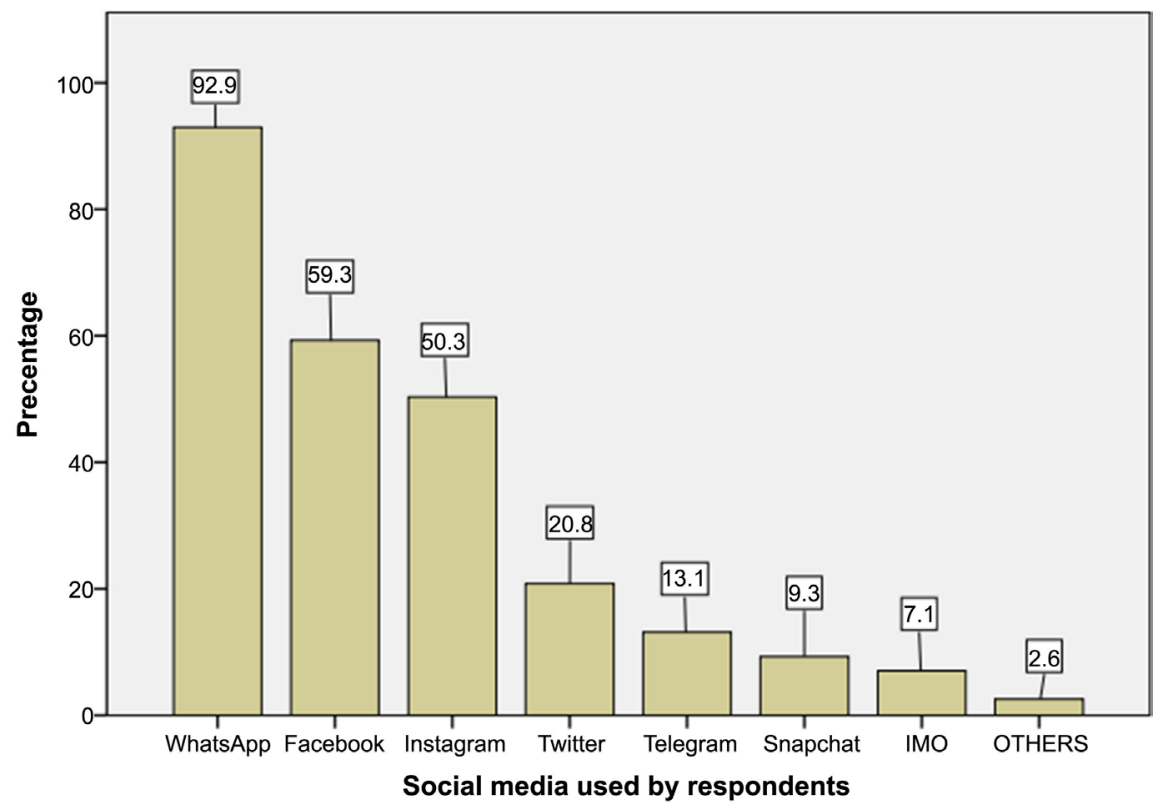

Figure 1. Social media used by undergraduate students.

respondents; 65 (20.8\%) listed Twitter; Telegram was listed by 41 (13.1\%); Snapchat was listed by 29 (9.3\%); 22 (7.1\%) listed IMO and 8 (2.6\%) listed under Others: Google Duo, LinkedIn, Viber, Line, Skype, WeChat, Messenger, TikTok and Weibo.

The respondents were further asked to state the technology which they mostly used in perpetrating CDA. Of the 279 responses provided to this question, $72.1 \%$ indicated they frequently used WhatsApp while 36.1\% used SMS. 8\%) used phone calls, minority 5.3\% used Facebook messenger while $2.9 \%$ used the others.

\section{Forms of Cyber Dating Abuse Behaviours Experienced by Undergraduate Students in Selected Universities in Nairobi City County}

The study also sought to find out what CDA behaviours were prevalent among undergraduate students. The data indicated that of the 315 respondents with dating experience, $284(90.2 \%)$ claimed to have perpetrated at least one of the behaviours in the CDA perpetration scale while a minority 31 (9.8\%) had not done so. 275 (87.3\%) had experienced at least one of the behaviours in the victimization scale, with a very small number 40 (12.7\%) reporting not to have experienced any of this. Table 4 illustrates the percentage of respondents who had experienced each of the CDA behaviours.

The results in Table 4 indicate that some CDA behaviours were prevalent among the respondents. Monitoring and controlling behaviours were the most common as $64.1 \%$ of the respondents reported of being pressured by a partner to respond quickly to calls, texts or other messages while $69.4 \%$ perpetrated this. $58.7 \%$ of the respondents reported that their partners monitored their whereabouts 
Table 4. Prevalence of CDA victimization per behaviour among dating respondents.

\begin{tabular}{|c|c|c|c|c|c|c|c|c|}
\hline \multicolumn{9}{|c|}{ Have you ever been a victim of CDA? } \\
\hline & \multicolumn{4}{|c|}{ Perpetration } & \multicolumn{4}{|c|}{ Victimization } \\
\hline & \multicolumn{2}{|c|}{ Yes } & \multicolumn{2}{|c|}{ No } & \multicolumn{2}{|c|}{ Yes } & \multicolumn{2}{|c|}{ No } \\
\hline & $\mathrm{F}$ & $\%$ & $\mathbf{F}$ & $\%$ & $\mathbf{F}$ & $\%$ & $\mathbf{F}$ & $\%$ \\
\hline Accessed online accounts & 164 & 52.1 & 151 & 47.9 & 158 & 50.2 & 157 & 49.8 \\
\hline Sent insulting message & 127 & 40.3 & 188 & 59.7 & 98 & 31.1 & 217 & 68.9 \\
\hline Spread rumours, gossip jokes & 66 & 21.2 & 245 & 78.8 & 69 & 22.0 & 244 & 78.0 \\
\hline Posted status/comments to elicit jealousy & 92 & 29.2 & 223 & 70.8 & 95 & 31.1 & 220 & 69.8 \\
\hline Threats of physical harm & 22 & 7.0 & 293 & 93.0 & 33 & 10.5 & 282 & 89.5 \\
\hline Sent message to threaten them & 49 & 15.6 & 265 & 84.4 & 55 & 17.5 & 259 & 82.5 \\
\hline Used information from SNS to ridicule partner & 70 & 22.2 & 245 & 77.8 & 68 & 21.6 & 247 & 78.4 \\
\hline Pressure for quick response & 218 & 69.4 & 96 & 30.6 & 202 & 64.1 & 113 & 35.9 \\
\hline Monitoring partner's whereabouts & 199 & 63.2 & 116 & 36.8 & 185 & 58.7 & 130 & 41.3 \\
\hline Too many messages making partner uncomfortable & 148 & 47.0 & 167 & 53.0 & 166 & 52.7 & 149 & 47.3 \\
\hline Pressure for passwords & 85 & 27.1 & 229 & 72.9 & 117 & 37.3 & 197 & 62.7 \\
\hline Snooped on partner's messages, call logs & 164 & 52.1 & 151 & 47.9 & 174 & 55.2 & 141 & 44.8 \\
\hline Pressure to sext & 55 & 17.5 & 260 & 82.5 & 68 & 21.6 & 247 & 78.4 \\
\hline Shared intimate information without permission & 50 & 15.9 & 264 & 84.1 & 53 & 16.9 & 261 & 83.1 \\
\hline $\begin{array}{l}\text { Pressured to have sex or engage in sexual activities } \\
\text { online }\end{array}$ & 76 & 24.1 & 239 & 75.9 & 88 & 28.0 & 226 & 72.0 \\
\hline Sent sexual photo partner did not ask for & 32 & 10.2 & 283 & 89.8 & 45 & 14.3 & 269 & 85.7 \\
\hline
\end{tabular}

and activities while 63.2 perpetrated it. $55.2 \%$ of the respondents reported that their partners snooped (spied) on their messages and call logs while $52.1 \%$ perpetrated it. $52.7 \%$ reported that they were sent so many messages that they felt uncomfortable while 47 perpetrated this. Majority of the respondents reported that victimization caused them depression, anxiety and fear. Some admitted that instances of CDA victimization negatively impacted on their academic engagement as they reported skipping classes, failing to pay attention in class and handing in assignments.

The study applied the Routine Activities Theory propounded by Lawrence Cohen and Marcus Felson in 1979 to understand the contribution of digital media in perpetration of CDA. The study findings indicate that the use of phone calls, text messages and instant messages via social media exposed vulnerable victims to a motivated offender. The respondents reported that they spent on average 18 hours and 5 minutes with $44.1 \%$ spending 24 hours 30 minutes per week on social media. This extensive use of digital media every week increased their visibility and accessibility to the offender.

All this social interaction happened in the absence of a capable guardian. To start with, most of the abusive behaviours were condoned by the respondents as 
being normal in their romantic relationships. This made majority of them to take the abuse lightly and not to seek help. In Kenyatta University, despite the availability of social media policy victims hardly referred to it for protection against CDA. Multimedia University of Kenya and Catholic University of Eastern Africa did not have a social media policy to regulate the use of social media among students and protect them against abuse.

Secondly, respondents did not involve their parents and university authorities in their affairs. They kept their affairs private and were silent on their abuse as some claimed they were not aware of how and to whom to report to. Even when facing abuse, they were reluctant to seek help from relevant authorities out of ignorance (majority of the respondents thought CDA was a normal part of relationships) and out of fear of exposing and causing themselves embarrassment. Many also held the belief that they were capable of handling their own issues. Findings revealed that many were reluctant to seek help from the university counsellors who they felt did not really understand them. However, the few who did, did so when the cases had got out of hand. This implied that the adults in the students' life could not act as capable guardians.

Results also indicated that the respondents preferred seeking help from friends to University Counsellors. From the FGD, it was reported that at times, friends could stand up for their friends by practicing collective revenge. In such instances, friends ganged against a friend's offending partner by putting up suggestive posts or insulting comments to humiliate them in defense of one of their own. A female respondent explained: "When you touch me, you touch all of us. So, when one of our friends comes crying, 'he has done this to me', me and my crew go for him...". This implied that the females used technology to get back at the offender. This assertion was unanimously corroborated by other female respondents who reported that it was at times necessary to do so. This reaction underscores friends' failure to deter the abuse but instead contributed to making things worse.

\subsection{Discussion on the Kinds of Digital Media Used in Perpetrating Different Forms of CDA among Kenyan Undergraduate Students}

The study purposed to find out the type of digital technologies used by the respondents for communication in their relationships and, in turn, what was frequently used to perpetrate CDA. From the findings, all respondents with dating experience owned mobile phones and $99.7 \%$ used them to access the internet. This was consistent with the findings by Reed et al. (2016) who found out that $100 \%$ of their respondents owned mobile phones. However, the percentage in this study was higher than that in previous studies on Kenyan university students. The study by Octutu et al. (2014) established that $75 \%$ of the 300 University of Nairobi students owned smartphones while the study by Mayoyo et al. (2015) of 143 Kisii University students found out that 122 (85.3\%) owned smartphones. 
This implied that with the passing years more and more students now own smartphones. This could be attributed to accessibility to readily available cheap smartphones in Nairobi City, a commercial hub. Besides, the price of smartphones had greatly dropped, making them quite affordable unlike some few years ago. Moreover, a report by the Communication Authority of Kenya (CAK) for the second quarter sector statistics for the financial year 2018/2019 indicated that there had been an exponential growth in the Kenyan mobile market over the years. Also, the internet/data market in the country remained vibrant during the quarter under review and the mobile phone remained the most available and preferred medium for accessing the internet (CAK, 2018).

The respondents said that they used SMS, phone calls and social media to get in touch with their partners. Most of them (94.2\%) sent text messages daily ranging from 20 - 500 texts. On the contrary, only $46.1 \%$ called several times a day while $52.9 \%$ called their partners at least once a day. It was, therefore, evident that most of them preferred exchanging texts to calling. This could be attributed to the fact that sending SMS is cheaper compared to making phone calls. The availability of flexible options by service providers made this possible where, for instance, one service provider offered SMS bundles at 30 shillings for 400 SMSs for a week or 200 SMS at 10 shillings daily. Texting was also found to be convenient because it was more private than calling at most times. Making phone calls did not afford them the privacy they desired, especially when in public places which were the case most of the times.

Also, results indicated that majority had access and communicated through social media with their partners. Half of the respondents spent over three hours on the social media on a typical day while a third spent between 1 and 3 hours. This time increased on the weekend as $65.7 \%$ of the respondents spent more than 3 hours on social media. This finding was expected since most students were free during weekends and could afford to spend more of their time online connecting with their friends and partners. The average time spent on the social media per week was 18 hours 5 minutes, though some respondents spent more than this, for example, $44.1 \%$ who spent 24 hours 30 minutes weekly.

Also, the respondents were found to use more than one social media with WhatsApp being the most favourite among them as listed by 278 (93.6\%). Facebook was the second favourite listed by 113 (38.0\%). Equally, WhatsApp was reported to be the most frequently used social media in perpetrating CDA as reported by $72.1 \%$ of the respondents. SMS was the second most frequently used reported by $36.1 \%$ of the respondents. Only $17.8 \%$ used phone calls while $5.3 \%$ used Facebook. These findings concur with those by Borrajo et al. (2015a) who found out that messaging services like WhatsApp were used in perpetrating over $50 \%$ of the reported cases of Cyber Dating Abuse with Facebook being used by $40 \%$ of the cases. It also concurs with findings by Burke et al. (2011) who found out that $40.9 \%$ of CDA behaviours among their respondents were carried out through messaging applications like WhatsApp. Baker and Carreno (2015) found out that texts and posts on FB were mostly used. Instagram and Tumblr 
were also used with less frequency.

However, while the respondents in the reviewed studies mostly used social networking sites to perpetrate more than half of the total behaviours (52.04\%) and e-mail for $7.04 \%$ of the behaviours, our study points to the contrary. Only $5.3 \%$ used Facebook while e-mail was not listed. This could be attributed to the difference in years that have elapsed since the Burke study of 2011. Technology has since evolved, and individuals find instant messaging and texting to be more convenient in communicating with partners because of their synchronous nature. Although texting is asynchronous, it can be used synchronously with correspondents exchanging several texts in succession. This is made possible due to the SMS bundles offer by mobile providers which enable users to exchange several texts a day at an affordable rate. Also, unlike e-mails which are asynchronous and may take time to reply, instant messaging guarantees the sender an instant response when the recipient is online which was the case with these respondents most of the times.

In this study, the findings indicated that instant messaging applications (specifically WhatsApp) were more popular than social networking sites like Facebook. Many smartphones nowadays come preinstalled with instant messaging applications like WhatsApp which makes it more likely to be used. Besides, it affords users privacy and many respondents claimed that it was fun to use because of the many emojis available. WhatsApp is also convenient to use even in instances when signal strength is weak and works well with any kind of network be it $2 \mathrm{G}, 3 \mathrm{G}$ or $4 \mathrm{G}$. The major difference between the different networks is the speed of data transmission with $4 \mathrm{G}$ offering the fastest internet browsing and data downloading compared to $3 \mathrm{G}$ and $2 \mathrm{G}$ networks.

The availability of internet on university campuses and some hostels meant that one could remain in touch wherever and with whatever networks they were in. This preference confirms that technology keeps evolving over time. A study by Mayoyo et al. (2015) showed that in the year 2014 Facebook was reported as the most favourite social networking site among Kisii University students as indicated by $93.7 \%$ of the respondents. Although Facebook has an instant messaging application, Messenger, which can be used to chat, many respondents clearly preferred WhatsApp over Messenger for their communication.

Overall, social media were the most common communication technology utilized by the respondents. This was made possible by the good connectivity in the three target universities because of availability of free Wi-Fi on campuses and in some student hostels. When not using free $\mathrm{Wi}$-Fi, students connected to internet by using mobile data bundles that were readily and cheaply available. Some of these were provided by mobile service providers while some used what they referred to as "bundles mwitu"-unconventional data bundles sold by resellers which were readily available on campuses and were much cheaper than those offered by conventional mobile service providers. Moreover, mobile data providers also offered free WhatsApp, Facebook and Twitter even upon depletion of data bundles so that one could remain connected for free. Besides connectivity, 
social media was popular because it offered the respondents privacy in their communication, it was fast, reliable, lively and more fun than sending SMS. The respondents enjoyed using emojis, posting statuses, exchanging photos and videos and video calling. This enhanced accessibility and flexibility encouraged respondents to constantly use social media, thus making them vulnerable to cyber dating abuse.

These findings revealed that the respondents' routine activities revolved around use of the technology. As indicated a considerable amount of time was spent using digital media and this extended use of technology was likely to expose them to CDA. A Pearson's Correlation Coefficient $r(313)=0.20, p \leq 0.001$ established that the amount of time spent online was statistically and significantly positively associated with higher CDA victimization. The $r$-value of 0.2 implied that this was practically significant (Felson, 2006). This therefore supported the hypothesis that the amount of time a victim spent online exposed them to a motivated offender, hence the higher their level of exposure, the higher their level of victimization. This concurs with the findings in a study by Baker and Carreno (2015), which found out that the use of technology, increased a victim's visibility even when they were not together and made it easy for a partner to abuse another.

This study further sought to find out the various forms of Cyber dating Abuse experienced by the victims. The findings show that the most common forms of CDA experienced were acts meant to monitor and control their partners and direct aggression in form of intrusiveness. Sexual coercion was the least common of the three. Intrusiveness included behaviours that infringed on partners' privacy and rights such as accessing without permission partner's mobile phone or online accounts and sending so many messages to a partner so that they felt uncomfortable. These findings concur with those in a study by Bennett et al. (2011) in which college students reported intrusion as a common form of CDA.

Monitoring and control were reflected in acts like accessing partners' messages to check whether they were behaving correctly (spying) and monitoring their whereabouts and activities. Also, pressuring them to respond quickly to calls, texts or other messages. This is in harmony with findings from studies that found out that monitoring was a common form of CDA among college students (Baker \& Carreno, 2015; Borrajo et al., 2015a; Draucker \& Martsolf, 2010; Daslakuk, 2016). A study by Lucero et al. (2014) also established that monitoring and sharing passwords were common forms of CDA. However, while Lucero and colleagues' study found sexting to be quite common, this was not the case in our study as only $68(21.6 \%)$ had been a victim of this and 55 (17.5\%) had perpetrated this. Sexual coercion was the least common form of CDA reported. This could be attributed to cultural differences and socialization. In most African cultures, talk about sex is a taboo and so some respondents may have feared being stigmatized or they simply could not have been involved.

Both females and males were monitored and controlled by their partners. This could be attributed to the frequent use of technology which provided an oppor- 
tunity for either party to control their partners. This concurs with Melander (2010) who found out that abuse involving control could be strengthened and aided using technology. Cyber Dating Abuse which was typically perpetrated technologically gave equal power to males and females involved in a relationship to control each other.

The study applied the Routine Activities Theory propounded by Cohen and Felson (1979) to understand CDA among undergraduate students. In the context of this paper, it was conceptualized that the youth's routine activities which revolve around use of technology expose them to CDA. All these happen in the absence of a guardian who could act in a protective manner or without a source of security systems like social media policy to deter the offence. The findings indicated that the respondents used a variety of digital media in their social interactions. It was in this interaction that offenders were able to encounter suitable victims (in this case their partners). The respondents reported that they spent considerable amount of time on social media every week which increased their visibility and accessibility to the offender.

It was evident from the findings in this study that the respondents' interaction with their partners happened in the absence of a capable guardian who could prevent the abuse. First, findings from the FGD showed that some respondents were not even aware that what they were experiencing was abuse as revealed by majority's misconception regarding behaviours constituting cyber dating abuse. This explained why CDA was prevalent among the respondents. This is in agreement with the assertion by Francis and Pearson (2019) that the failure by young people to recognize abusive behaviours increased their chance of being victims of dating abuse. This was compounded by the fact that even in Kenyatta University which had a social media policy in place, majority of the respondents generally lacked awareness of its existence. Consequently, although the policy was capable of offering protection to victims, it did not, as victims hardly made reference to it and did not report CDA victimization to the administration. Besides, the study found out that Multimedia University of Kenya and Catholic University of Eastern Africa did not have anti-cyber abuse policies and relied on the student code of conduct to handle cases of CDA. This implied that there was a need for universities to include CDA in existing policies such as the social media policy and in policies on sexual harassment and interpersonal violence within university settings. Students should be sensitized on CDA so that they are able to recognize it and take advantage of available help as part of intervention measures.

Secondly, many respondents treated most of the CDA cases lightly and relied on the advice of their friends who were just as ignorant as those seeking help and, in some cases, just worsened the CDA cases. This implied that even friends who were regularly consulted or told of the abuse were not able to deter or stop the crime in progress. This called for awareness training on CDA so that friends who are consulted are able to recognize abuse. This would play a role in equipping them skills and knowledge to enable them act as capable guardians and minimize abuse hence mitigate the negative effects of CDA among undergraduate 
students.

Thirdly, although all the respondents reported to have computer competency, it remained unclear whether their parents and university officials who could act as capable guardians possessed computer competency. It was also reported that parents and most university officials were not aware of the nature of digital interactions the respondents had with their partners. Besides, young people have been found to want to keep secret their conversations by using language that may be foreign to adults. For instance, IWSN which means "I Want Sex Now"; GNOC which means "Get Naked on Camera"; TDTM which means "Talk Dirty to $\mathrm{Me}$ " could constitute sexual coercion abuse which might go unrecognized by adults. This implied that in such circumstances they could not act as capable guardians with authority to monitor what the respondents did online to ensure civility. Additionally, young adults in the university enjoy a lot of freedom in their use of technology free of monitoring by authorities and parents. This explained why it was unlikely that those in authority could intervene in cases of abuse unless the victims themselves sought help.

Finally, many respondents stated that they sought for help from their peers. Despite possessing computer competency these peers often did nothing to stop CDA. It was reported that most times some friends and classmates were responsible for making revenge porn go viral by redistributing private pictures and videos among their friends and classmates. Such acts did nothing to stop CDA but only fuelled it further making things worse.

\subsection{Conclusion}

Based on the results from this study, it is concluded that the respondents' routine activities involved constant exchange of calls, SMS, online chats providing avenues for CDA victimization. This arose out of the need by the respondents to remain connected with their romantic partners using digital media. Equally, the need by the young adults to correspond with their partners in "real time" led them to majorly use instant messaging in their communication. Consequently, WhatsApp was the most common kind of digital technology used in perpetrating CDA. This extensive use of technology led to higher chances of victimization as it increased the victims' visibility. Since digital media is here to stay and hence CDA victimization is likely to persist, future research could involve an in-depth longitudinal study of CDA so as to understand it better for preventive measures. The findings indicated that the existence of social media policy is not enough to deter CDA, consequently students should be enlightened on how they can use Social Media Policy to guide their interactions and protect them from abuse. Universities should also provide education through awareness training on risks involved as part of intervention and preventive measures. Guidance and counselling to promote healthy dating should also be provided.

\section{Conflicts of Interest}

The authors declare no conflicts of interest regarding the publication of this paper. 


\section{References}

Baker, C. K., \& Carreno, P. K. (2015). Understanding the Role of Technology in Adolescent Dating and Dating Violence. Journal of Child and Family Studies, 25, 308-320. https://doi.org/10.1007/s10826-015-0196-5

Bennett, D. C., Guran, E. L., Ramos, M. C., \& Margolin, G. (2011). College Students' Electronic Victimization in Friendships and Dating Relationships: Anticipated Distress and Associations with Risky Behaviours. Violence and Victims, 26, 410-429.

https://doi.org/10.1891/0886-6708.26.4.410

Borrajo, E., Gámez-Guadix, M., Pereda, N., \& Calvete, E. (2015a). Cyber Dating Abuse: Prevalence, Context, and Relationship with Offline Dating Aggression. Psychological Reports, 116, 565-585. https://doi.org/10.2466/21.16.PR0.116k22w4

Borrajo, E., Gámez-Guadix, M., Pereda, N., \& Calvete, E. (2015b). The Development and Validation of the Cyber Dating Abuse Questionnaire among Young Couples. Computers in Human Behaviour, 48, 358-365. https://doi.org/10.1016/j.chb.2015.01.063

Burke, S. C., Wallen, M., Vail-Smith, K., \& Knox, D. (2011). Using Technology to Control Intimate Partners: An Exploratory Study of College Undergraduates. Computers in Human Behaviour, 27, 1162-1167. https://doi.org/10.1016/j.chb.2010.12.010

CAK (2018). Second Quarter Sector Statistics Report for the Financial Year 2018/2019 (October-December 2018). http://www.ca.go.ke

Cohen, L. E., \& Felson, M. (1979). Social Change and Crime Rate Trends: A Routine Activity Approach. American Sociological Review, 44, 588-608. https://doi.org/10.2307/2094589

Daslakuk, S. (2016). Cyber Dating Abuse: How Coercive Control and Attitudes about Dating Aggression Affect Health and Relationship Quality (p. 5809). Electronic Theses and Dissertations. http://scholar.uwindsor.ca/etd/5809

Draucker, C. B., \& Martsolf, D. S. (2010). The Role of Electronic Communication Technology in Adolescent Dating Violence. Journal of Child and Adolescent Psychiatric Nursing, 23, 133-142. https://doi.org/10.1111/j.1744-6171.2010.00235.x

Felson, M. (2006). Crime and Nature. Thousand Oaks, CA: Sage.

Francis, L., \& Pearson, D. (2019). The Recognition of Emotional Abuse: Adolescents' Responses to Warning Signs in Romantic Relationships. Journal of Interpersonal Violence. https://doi.org/10.1177/0886260519850537

Lucero, J. L., Weisz, A. N., Smith-Darden, J., \& Lucero, S. M. (2014). Exploring Gender Differences Socially Interactive Technology Use/Abuse among Dating Teens. Affilia, 29, 478-491. https://doi.org/10.1177/0886109914522627

Mayoyo, N., Nyang'au, T. N., Nyamwaka, E., \& Aminga, N. N. (2015). An Assessment of the Extent of Facebook Use by Students at Kisii University, Kenya and Its Implication on Educational Activities. British Journal of Education, Society and Behavioural Science, 7, 165-175. https://doi.org/10.9734/BJESBS/2015/15983

Melander, L. A. (2010). College Students' Perceptions of Intimate Partner Cyber Harassment. Cyberpsychology, Behaviour, and Social Networking, 13, 263-268.

https://doi.org/10.1089/cyber.2009.0221

Octutu, A., Martita, A., Nyakerario, F. E., Wanekeya, R., \& Akotii, J. E. (2014). Mobile Phone Usage among University Students in Kenya: A Case Study of the University of Nairobi. School of Journalism and Mass Communication, University of Nairobi.

Picard, P. (2007). Tech Abuse in Teen Relationships. Chicago, IL: Teen Research Unlimited.

Reed, L. (2015). Digital Dating Abuse: Digital Media as a Gendered Context for Dating 
Violence in the Digital World. Unpublished PhD Thesis, Ann Arbor, MI: University of Michigan.

Reed, L. A., Tolman, R. M., \& Safyer, P. (2015). Too Close for Comfort: Attachment Insecurity and Electronic Intrusion in College Students' Dating Relationships. Computers in Human Behaviour, 50, 431-438. https://doi.org/10.1016/j.chb.2015.03.050

Reed, L. A., Tolman, R. M., \& Ward, L. M. (2016). Snooping and Sexting: Digital Media as a Context and Tool for Dating Violence among College Students. Violence against Women, 22, 1556-1576. https://doi.org/10.1177/1077801216630143

Vermaat, M. E. (2014). Enhanced Discovering Computers. Computer Education/Instructional Technology Shelly Cashman Series. Boston, MA: Cengage Learning. 